\title{
Femtosecond VECSELs with up to 1-W Average Output Power
}

\author{
M. Hoffmann'1, O. D. Sieber'1, V. J. Wittwer'1, W. P. Pallmann'1, I. L. Krestnikov², S. S. Mikhrin², \\ D. A. Livshits ${ }^{2}$, M. Golling1, Y. Barbarin'1, T. Südmeyer ${ }^{1}$ and U. Keller ${ }^{1}$ \\ 1. Department of Physics, Institute of Quantum Electronics, ETH Zurich, 8093 Zurich, Switzerland \\ 2. Innolume GmbH, Konrad-Adenauer-Allee 11, 44263 Dortmund, Germany
}

Since the first demonstration of passively modelocked VECSELs, their performance in terms of output power, repetition rate and pulse duration substantially improved. Recently, up to $6.4 \mathrm{~W}$ of average power in 28ps pulses were achieved from a modelocked VECSEL with an integrated saturable absorber (MIXSEL, [1]). The shortest pulse duration generated by a VECSEL was $60 \mathrm{fs}$ at less than $35 \mathrm{~mW}$ average output power in harmonic modelocking [2]. To date, femtosecond VECSELs were based on quantum well (QW) gain structures and the average output power has been limited to $<150 \mathrm{~mW}$ [3] (Fig. 1a). In contrast, so far modelocked VECSELs based on quantum dot (QD) gain structures have been restricted to 18 ps using QW-SESAMs [4].

Here we report on record-high average output power of a femtosecond VECSEL (Fig. 1a: 1 W, 784 fs) and present the first detailed study of femtosecond VECSELs modelocked by fast QD-SESAMs. We investigate the modelocking performance both for VECSELs with QD and QW gain structures. Based on our previous work on the influence of GDD on the pulse duration [5] we developed a top coating inspired by the work of Lumb et al. [6]. The top coating consists of $6 \mathrm{AlAs} / \mathrm{AlGaAs}$ pairs and a fused silica layer on top. The thicknesses are optimized using a Monte Carlo algorithm combined with a standard optimization. This provides a flat GDD with values between $\pm 10 \mathrm{fs}^{2}$ over a range of $30 \mathrm{~nm}$ around the design wavelength (Fig. 1b) which is several orders of magnitude lower compared to previous designs. Furthermore, we used optimized positions of the gain layers in the standing wave pattern to broaden and flatten the spectral gain. The SESAM we used for the QWbased gain results has a standard resonant design with QD saturable absorber. This SESAM has a fast absorption recovery component in the order of $800 \mathrm{fs}$. However, for the QD-based gain results, the same SESAM was made antiresonant by depositing a quarter-wave layer of fused silica on top. This leads to a higher saturation energy of the SESAM, which allows higher power levels. Additionally, the GDD is lowered to $\pm 100 \mathrm{fs}^{2}$ in a $30 \mathrm{~nm}$ range around the design wavelength. All these design improvements enabled the first operation of a QDVECSEL in the femtosecond regime. We achieved for both QD- and QW-based gain structures a similar minimal pulse duration of $416 \mathrm{fs}$ (QD) and $455 \mathrm{fs}(\mathrm{QW})$ with $140 \mathrm{~mW}$ (QD) and $110 \mathrm{~mW}(\mathrm{QW})$ average output power (Fig. 1b). Direct soldering of the QD-based gain chip onto a CVD diamond heat spreader and subsequent substrate removal enabled power scaling to $1-\mathrm{W}$ average power with a pulse duration of $784 \mathrm{fs}$ and a pulse repetition rate of $5.4 \mathrm{GHz}$. The peak power of $200 \mathrm{~W}$ in combination with the high average power makes this source attractive for numerous applications such as biomedical multi-photon imaging.
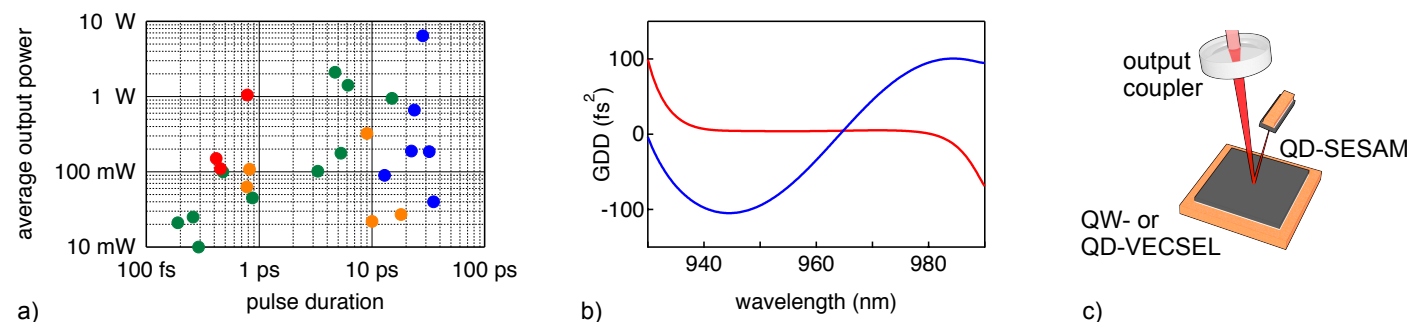

Fig. 1 a) Overview of ultrafast VECSEL results highlighting this paper's results (red). QW-VECSEL are indicated by green points, QD-VECSEL by orange points and the MIXSEL by blue points. b) GDD of the VECSEL structure (red) and of the antiresonant QD-SESAM (blue). c) Experimental setup consisting of the output coupler, the QW- or QD-

\section{References} VECSEL and the QD-SESAM.

[1] B. Rudin, V. J. Wittwer, D. J. H. C. Maas, M. Hoffmann, O. D. Sieber, Y. Barbarin, M. Golling, T. Südmeyer, and U. Keller, "Highpower MIXSEL: an integrated ultrafast semiconductor laser with $6.4 \mathrm{~W}$ average power," Opt. Express 18, 27582-27588 (2010).

[2] A. H. Quarterman, K. G. Wilcox, V. Apostolopoulos, Z. Mihoubi, S. P. Elsmere, I. Farrer, D. A. Ritchie, and A. Tropper, "A passively mode-locked external-cavity semiconductor laser emitting 60-fs pulses," Nat. Photonics 3, 729-731 (2009).

[3] K. G. Wilcox, A. H. Quarterman, H. Beere, D. A. Ritchie, and A. C. Tropper, "High Peak Power Femtosecond Pulse Passively ModeLocked Vertical-External-Cavity Surface-Emitting Laser," Photonics Technology Letters, IEEE 22, 1021-1023 (2010).

[4] M. Hoffmann, Y. Barbarin, D. J. H. C. Maas, M. Golling, I. L. Krestnikov, S. S. Mikhrin, A. R. Kovsh, T. Südmeyer, and U. Keller, "Modelocked quantum dot vertical external cavity surface emitting laser," Appl. Phys. B 93, 733-736 (2008).

[5] M. Hoffmann, O. D. Sieber, D. J. H. C. Maas, V. J. Wittwer, M. Golling, T. Südmeyer, and U. Keller, "Experimental verification of soliton-like pulse-shaping mechanisms in passively mode-locked VECSELs," Opt. Express 18, 10143-10153 (2010).

[6] M. Lumb, P. Stavrinou, E. Clarke, R. Murray, C. Leburn, C. Jappy, N. Metzger, C. Brown, and W. Sibbett, "Dispersionless saturable absorber mirrors with large modulation depths and low saturation fluences," Applied Physics B: Lasers and Optics 97, 53-60 (2009). 